\title{
IbDM PEMANFAATAN TEKNOLOGI DALAM PENGEMBANGAN PRODUK "ATUN" SEBAGAI OLAHAN KHAS NAGARI LUBUK BESAR, KABUPATEN DHARMASRAYA
}

\author{
Cesar Welya Refdi*, Novelina, Ismed, Daimon Syukri, Felga Zulfia Rasdiana, Wellyalina
}

Jurusan Teknologi Hasil Pertanian, Fakultas Teknologi Pertanian, Universitas Andalas

email: cesarwelya@ae.unand.ac.id

\begin{abstract}
ABSTRAK
Kabupaten Dharmasraya yang terdapat hampir disepanjang jalan lintas Sumatera belum dikenal makanan khasnya. Makanan yang biasa dijadikan oleh-oleh hanya keripik tempe. Di Nagari Lubuk Besar terdapat produk olahan khas yang biasa disajikan pada acara-acara adat dan pernikahan, yaitu Atun. Sebagian ibu-ibu dari masyarakat Nagari Lubuk Besar hanya mampu menjual produk ini sesekali pada 'hari pasa' (jadwal pasar tradisional), karena permasalahan umur simpan produk yang singkat yaitu 1-2 hari. Hal ini juga yang menjadi kendala Atun dijadikan sebagai oleh-oleh khas Kabupaten Dharmasraya. Teknologi pengemasan vakum adalah sistem pengemasan hampa udara sehingga memperpanjang umur simpan, sehingga produk akan lebih bertahan 2-3 kali lebih lama daripada produk yang yang disimpan dengan nonvakum. Selain itu, pembuatan produk Atun Instan dapat bertahan lebih lama dan menjadi inovasi agar Atun dapat dikonsumsi oleh konsumen yang lebih jauh. Tujuan dari kegiatan IbDM ini secara umum adalah meningkatkan pengetahuan, keterampilan, kemandirian dan semangat berwirausaha bagi anggota kelompok Wanita "Lubuk Besar Bersinar" yang tergabung dalam Kelompok PKK Nagari Lubuk Besar dengan aplikasi teknologi. Dalam pengembangan produk atun ini dilakukan transfer teknologi dalam bentuk pelatihan teknologi pengemasan hampa dan penyimpanan, pembuatan atun instan, serta penyuluhan pemasaran dan manajemen bisnis Atun dalam mengembangkan produk Atun sebagai oleh-oleh khas Nagari Lubuk Kabupaten Dharmasraya.
\end{abstract}

Kata Kunci: Atun, Atun Instan, Pengemasan Vakum, Makanan Tradisional

\section{ABSTRACT}

Dharmasraya District, located almost along the trans-Sumatra road, is not yet known for its traditional food. Food that is used as gifts is only tempeh chips. At Lubuk Besar Village, a village of Dharmasraya, there are typically snack usually served at traditional events and weddings, namely Atun. Some woman from the community of Nagari Lubuk Besar are only able to occasionally sell this product on 'Pasa Day' (traditional market schedule) because of the short shelf life of the product, which is 1-2 days. It also became Atun's obstacle as a souvenir of the Dharmasraya District. Vacuum packaging technology is a packaging system without oxygen that extends shelf life so that products will last 2-3 times longer than non-vacuum stored products. Additionally, Instant Atun products' production can last longer and become an innovation so that more distant consumers can consume Atun. This IbDM program aims to increase knowledge, skills, independence, and an entrepreneurial spirit for members of the "Lubuk Besar Bersinar" Women group and the Lubuk Besar PKK Group with the application of technology. In developing Atun product, technology transfer is carried out in the form of training on vacuum packaging and storage technology, making instant Atun, and counseling on Atun's marketing and business management in developing Atun products as souvenirs from Dharmasraya District.

Keywords: Atun, Instan Atun, Vacuum Packaging, Traditional Food

PENDAHULUAN

Kenagarian Lubuk Besar merupakan salah satu kenagarian yang berada di wilayah \pm 18.700 Ha. Secara administrasi, kenagarian pemerintahan Kecamatan Asam Jujuhan Lubuk Besar memiliki daerah batasan sebagai
Kabupaten Dharmasraya. Kenagarian Lubuk Besar ini memiliki luas wilayah kurang lebih 199 
berikut: Sebelah Utara: Kecamatan Sangir Balai Janggo,Sebelah Selatan: Kecamatan Limbur Lubuk Mangkuang, Sebelah Timur: Provinsi Nagari Alahan Nan Tigo, Sebelah Barat: Kerinci Jambi.

Nagari Lubuk Besar dikelilingi oleh perkebunan sawit baik perkebunan milik perusahaan maupun milik masyarakat. Kenagarian Lubuk Besar berdasarkan administrasi pemerintahannya memiliki 4 Jorong, yaitu sebagai berikut: Jorong Lubuk Besar, Jorong Mangun Jaya, Jorong Koto Ubi, Jorong Sei Betung. Mayoritas masyarakat yang hanya menjadi petani dan buruh kebun terjadi karena kurangnya pengetahuan dan keterampilan wirausahata masyarakat termasuk pada ibu-ibu yang berkumpul pada kelompok wanita dan kelompok PKK Nagari Lubuk Besar.

Kabupaten Dharmasraya yang terdapat hampir disepanjang jalan lintas Sumatera merupakan tempat persinggahan bagi kendaraan antar provinsi dan antar pulau. Kabupaten ini juga mulai berkembang pariwisatanya. Namun jika ditelusuri makanan khas Dharmasraya sebagai makanan oleh-oleh masih beum ada. Bupati Dharmasraya, Sutan Riska Tuanku Kerajaan, pada media Metro Andalas menyatakan sangat mengharapkan setiap daerah (nagari) mengembangkan produk khas daerah, karena makanan khas unggulan yang diketahuinya saat ini hanyalah keripik tempe.

\section{Di Kabupaten Dharmasraya khususnya} Nagari Lubuk Besar, terdapat produk olahan khas yang biasa disajikan pada acara-acara adat dan pernikahan, yaitu Atun. Produk ini adalah olahan tepung beras yang diolah menggunakan bambu sebagai kemasan pengolahannya. Produk ini belum banyak dikenal orang. Sebagian ibuibu dari masyarakat Nagari Lubuk Besar hanya mampu menjual produk ini sesekali apabila ada pesanan atau pada 'hari pasa' (jadwal pasar tradisional ramai), karena permasalahan yang dihadapi masyarakat adalah umur simpan produk yang singkat. Hal ini juga yang menjadi kendala Atun dijadikan sebagai oleh-oleh khas Kabupaten Dharmasraya.

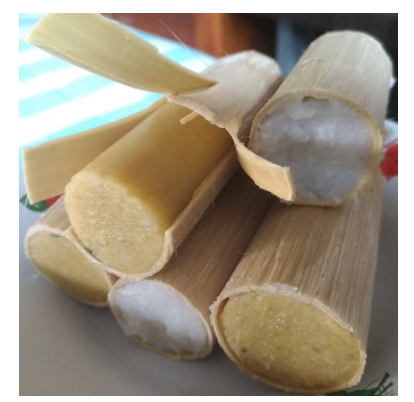

Gambar 1. "ATUN" makanan khas Nagari Lubuk Besar, Kabupaten Dharmasraya

Makanan olahan seperti atun merupakan pangan basah, yang umur simpannya sangat singkat sekitar 1-2 hari. Teknologi pengemasan dan penyimpanan diharapkan dapat menjadi solusi dalam meningkatkan umur simpan produk. Pengemasan merupakan salah satu proses dalam industri yang memegang peranan penting dalam upaya mencegah terjadinya penurunan mutu produk [1]. Pengemasan harus dilakukan dengan teknologi yang tepat, karena pengemasan yang salah dapat mengakibatkan produk menjadi tidak memenuhi syarat mutunya.

[2] melakukan penelitian untuk produk pangan semi basah yaitu mengenai jenis bahan pengemas dan lama penyimpanan terhadap mutu 
sifat kimia dan mikrobiologi dari sate bandeng. Penelitian ini menggunakan teknik pengemasan vakum dan non vakum. Hasil dari penelitian ini adalah menunjukkan pengemasan vakum dapat meningkatkan umur simpan sate bandeng dari 3 hari menjadi 6 hari [3].

Oleh karena itu, transfer teknologi terkait pengolahan, pengemasan dan penyimpanan diharapkan dapat meningkatkan nilai jual dan potensi Atun menjadi oleh-oleh makanan khas Kabupaten Dharmasraya, serta meningkatkan pendapatan masyarakat khususnya ibu-ibu.

Tujuan program pengabdian kepada masyarakat ini adalah:

a. Meningkatnya mutu dan umur simpan produk olahan khas Nagari Lubuk Besar "Atun" dengan aplikasi teknologi pengemasan vakum pada produk.

b. Meningkatnya jumlah produksi produk “Atun' dengan pembuatan variasi produk Atun Instan.

c. Menghasilkan produk atun dengan pengemasan dan pelabelan yang menarik.

d. Meningkatkan pengetahuan mitra tentang aspek wirausaha, dan pemasaran khususnya secara online (online shop).

e. Meningkatnya perekonomian masyarakat di Nagari Lubuk besar melaui wirausaha produk olahan khas Nagari Lubuk Besar sehingga bisa berkembang menjadi oleholeh khas di Kabupaten Dharmasraya.

Adapun Indikator Ketercapaian Program IPTEK bagi Dosen dan Masyarakat (IbDM) adalah :

1. Dari segi inovasi dan teknologi produk, ketercapaiannya antara lain : Adanya produk khas olahan Nagari yang menjadi peluang usaha, adanya produk khas dalam bentuk instan untuk meningkatkan tujuan konsumen, Kemasan Vacuum packaging yang meningkatkan umur simpan, serta penggunaan teknologi modren seperti Mesin Vacuum Packaging, Oven, Peralatan produksi.

2. Dari segi standarisasi dan legalitas, ketercapaiannya yaitu : mitra memahami tentang pengurusan legalitas usaha (PIRT, BPOM, Sertifikat Halal).

3. Dari segi ekonomi, ketercapaiannya yaitu : terjadinya pengembangan pasar berupa penjualan secara online dan offline, serta dapat meningkatkan penghasilan / omset usaha.

4. Dari segi sosial. Ketercapaiannya yaitu : Bagi masyarakat dapat meningkatnya semangat wirausaha serta pengetahuan baru tentang produk olahan khasnya, dan bagi pemerintah dapat memberikan bantuan terhadap masyarakat terkait program.

\section{METODE PELAKSANAAN KEGIATAN}

Kegiatan ini dilaksanakan dalam tiga bentuk kegiatan, yaitu penyuluhan, pelatihan dan bimbingan berkelanjutan.

\section{a. Penyuluhan}

Sebagai wirausaha baru yang bergerak di bidang pangan, mitra sebaiknya paham mengenai syarat-syarat produksi dan pemasaran produk pangan. Penyuluhan yang akan dilakukan mencakup pada teknik pengolahan 
yang benar (sanitasi) dan pelabelan sebagai syarat izin edar.

\section{b. Pelatihan}

Pelatihan yang akan dilakukan mencakup 2 materi, yaitu :

1) Pelatihan Vacuum Packaging and Storage Pelatihan Vacuum Packaging and Storage dapat dilakukan dengan workshop dan pelatihan teknik pengemasan hampa (vacuum packaging)dan penyimpanan secara frozen. Materi pelatihan yang diberikan meliputi :

- Pelatihan dan workshop tentang cara kerja mesin vacuum packaging yang benar

- Workshop tentang pengemasan dan penyimpanan pada berbagai metode dan bahan makanan.

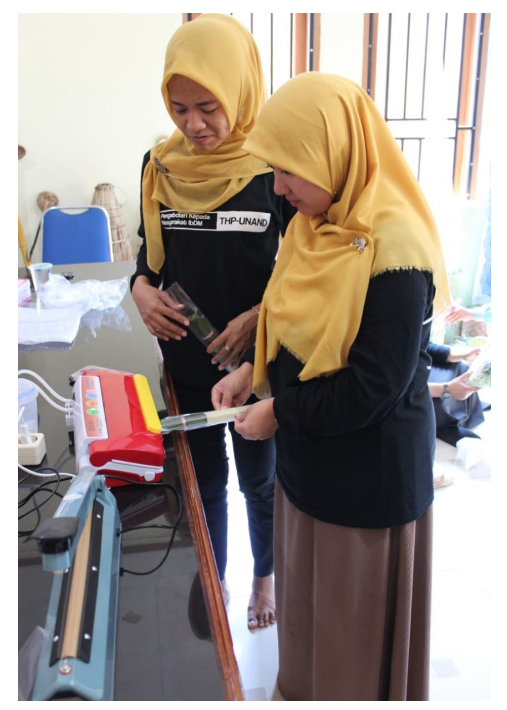

Gambar 2. Pelatihan Pengemasan Atun dengan Vacuum Packaging

2) Pelatihan Pembuatan Atun Instan

Pelatihan pembuatan atun dalam bentuk instan dapat ditawarkan kepada masyarakat agar Atun dapat dikonsumsi oleh konsumen yang lebih jauh.

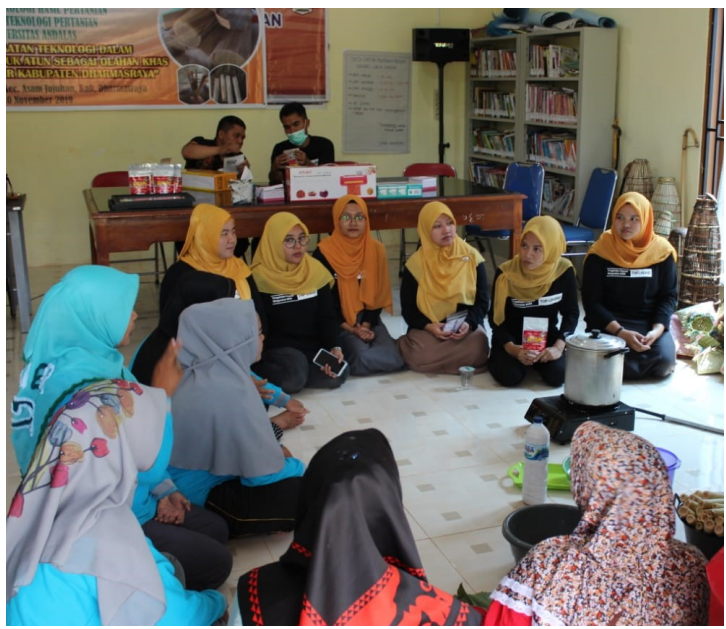

Gambar 3. Pelatihan Pembuatan Atun Instant

\section{c. Bimbingan Wirausaha}

Setelah proses penyuluhan dan pelatihan dilangsungkan, selanjutnya diberikan bimbingan terhadap penyelesaian kendala yang ada, kontinyuitas produksi, dan keaktifan media promosi yang digunakan.

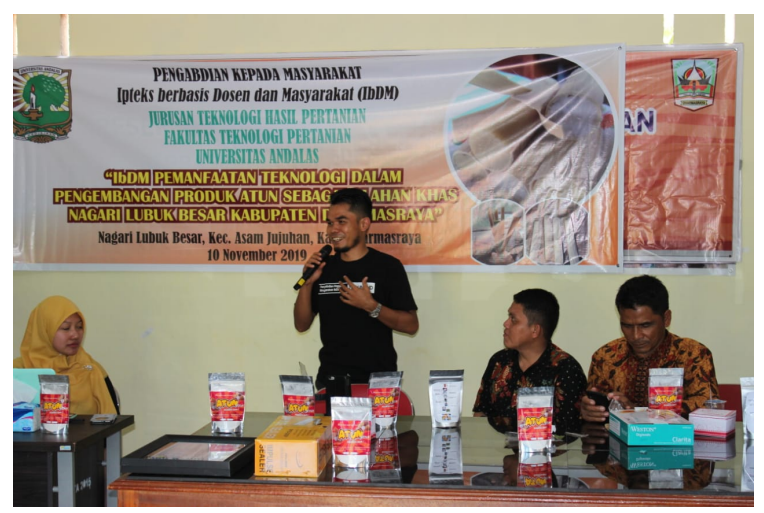

Gambar 4. Penyuluhan Manajemen Bisnis dan Pemasaran Atun sebagai Oleh-oleh Khas Dharmasraya

\section{HASIL DAN PEMBAHASAN}

Pengabdian kepada Masyarakata Program IPTEK berbasis Dosen dan Masyarakat ini didahului dengan pertemuan yang membahas tentang kebutuhan dan permalasahan mitra terkait prouk Atun sebagai olahan khas Nagari Lubuk Besar. Oleh karena itu dilakukan pelatihan dan penyuluhan pertama di Kantor 
Wali Nagari Lubuk Besar, Kecamatan Asam Jujuhan, Kabupaten Dharmasraya. Pelatihan yang dilakukan terdiri dari Pelatihan Pengemasan Hampa (Vacuum Packaging), Penyuluhan Pelabelan dan Legalisasi Pangan, serta Workshop Wirausaha Atun.

Kegiatan ini dibuka oleh Camat Asam Jujuhan, dan dihadiri oleh Pejabat di Nagari Lubuk Besar. Peserta Pelatihan yang hadir adalah Kelompok Wanita Lubuk Besar Bersinar dan Kelompok PKK Nagari Lubuk Besar.

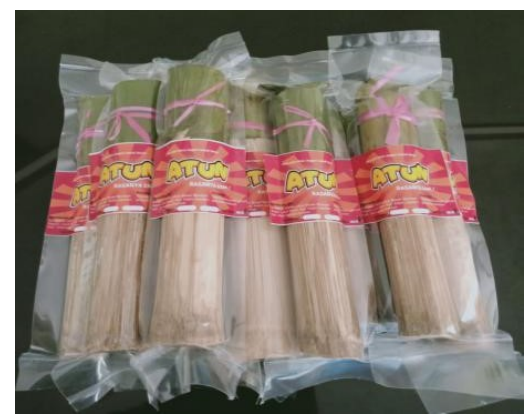

Gambar 5. Atun dalam Kemasan

Hasil dari kegiatan ini adalah produk Atun dengan kemasan vacum dan telah dilabel. Astawan et al., menyatakan diperlukannya komnbinasi pengemasan vakum dengan penyimpanan dingin ${ }^{2}$. Oleh karena itu, produk ini kemudian disimpan pada 3 suhu yang berbeda (suhu ruang, suhu dingin atau refrigerator dan suhu beku atau freezer). Dari pengamatan yang dilakukan, diperoleh data bahwa pengemasan vakum atun dan disimpan pada suhu ruang hanya meningkatkan umur simpan menjadi 1 hari, sedangkan penyimpanan pada suhu dingin (refrigerator) meningkatkan umr simpan 2 kali lipat, namun penyimpanan pada suhu beku (freezer) meningkatkan umur simpan hingga 7 hari dengan perubahan tekstur. Data lengkap terlihat pada Tabel 1.
Tabel 1. Hasil Pengamatan Umur Simpan Atun dalam Kemasan

\begin{tabular}{|c|c|c|c|}
\hline \multirow{2}{*}{ No } & \multirow{2}{*}{ Penyimpanan } & \multicolumn{2}{|c|}{ Umur Simpan } \\
\cline { 3 - 4 } & $\begin{array}{c}\text { Pengemasan } \\
\text { Non Vakum }\end{array}$ & $\begin{array}{c}\text { Pengemasan } \\
\text { Vakum }\end{array}$ \\
\hline 1. & suhu ruang & $\begin{array}{c}\text { Kurang dari } \\
1 \text { hari }\end{array}$ & 1 hari \\
\hline 2. & $\begin{array}{c}\text { suhu dingin } \\
\text { (refrigerator })\end{array}$ & 1 hari & 2 hari \\
\hline 3. & $\begin{array}{c}\text { suhu beku } \\
\text { (freezer })\end{array}$ & 3 hari* & 7 hari* \\
\hline
\end{tabular}

Kegiatan kedua dilaksanakan dalam bentuk Pelatihan pembuatan Atun Instant dan Workhsop Manajemen Bisnis Atun. Selain peserta dari Kelompok Wanita Lubuk Besar Bersinar, kegiatan ini dihadiri juga oleh Camat Asam Jujuhan, Ibu Ketua PKK Kecamatan Asam Jujuhan, Wali Nagari Lubuk Besar, Ibu Ketua PKK Nagari Lubuk Besar dan perangkat Nagari. Pada Pelatihan ini dilakukan pembuatan produk Atun Instan dan Pengolahan Atun Instan menjadi Atun.

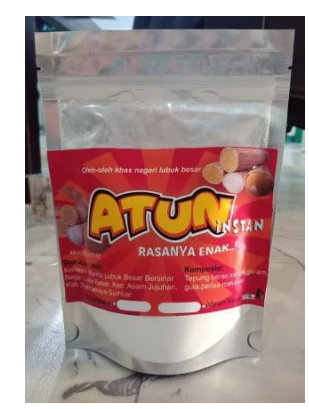

Gambar 6. Atun Instan

Peragaan pengemasan Atun dan pembuatan produk Atun Instan dilaksanakan dengan proses demonstrasi dan praktik langsung oleh para peserta. Penunjang peragaan produk ini tim memberikan bantuan alat-alat. Pelabelan untuk produk atun dalam kemasan dan atun intsant didesain oleh tim pengabdian masyarakat. Desain kemasan dicetak di kertas label. 


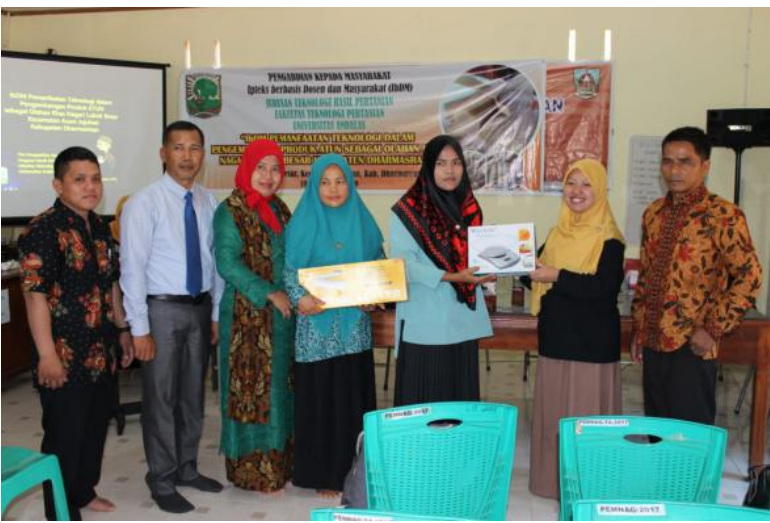

Gambar 7. Penyerahan Bantuan alat kepada Nagari Lubuk Besar, Kecamatan Asam Jujuhan, Kabupaten Dharmasraya

Luaran yang telah dicapai oleh program Pengabdian Iptek berbasis Dosen dan Masyarakat ini adalah:

1. Kelompok Wanita Lubuk Besar Bersinar dan Kelompok PKK Nagari Lubuk Berar mendapatkan pengetahuan dan keterampilan mengenai teknik pengemasan hampa (vacuum packaging) dan penyimpanan secara frozen.

2. Kelompok Wanita Lubuk Besar Bersinar dan Kelompok PKK Nagari Lubuk Besar mendapatkan pengetahuan dan keterampilan mengenai ATUN INSTAN sebagai salah satu inovasi ATUN khas Nagari Lubuk Besar.

3. Produk olahan yang dihasilkan yaitu Produk Atun dalam kemasan Vakum dan Tepung Atun Instan yang telah memiliki label dan layak untuk dipasarkan. Kemasan dan label yang telah didesain oleh tim Pengabdian Iptek berbasis Dosen dan Masyarakat.

\section{KESIMPULAN DAN SARAN}

\section{Kesimpulan}

Kesimpulan yang bisa diambil dari Program Pengabdian Iptek berbasis Dosen dan Masyarakat di Nagari Lubuk Besar Kecamatan Asam Jujuhan ini yaitu :

1. Program IbDM dilakukan dalam bentuk Pelatihan Vacuum Packaging and Storage yaitu workshop dan pelatihan teknik pengemasan hampa (vacuum packaging) dan penyimpanan secara frozen, dan Pelatihan Pembuatan Atun Instan, agar Atun dapat dikonsumsi oleh konsumen yang lebih jauh. Selain itu, juga dilakukan workshop dan penyuluhan dalam rangka Bimbingan Wirausaha Produk Atun.

2. Kelompok Wanita Lubuk Besar Bersinar dan Kelompok PKK Nagari Lubuk Berar mendapatkan pengetahuan dan keterampilan mengenai teknik pengemasan hampa (vacuum packaging) dan penyimpanan secara frozen.

3. Kelompok Wanita Lubuk Besar Bersinar dan Kelompok PKK Nagari Lubuk Berar mendapatkan pengetahuan dan keterampilan mengenai ATUN INSTAN sebagai salah satu inovasi ATUN khas Nagari Lubuk Besar.

4. Luaran IPTEK yang telah dicapai oleh program Pengabdian Iptek berbasis Dosen dan Masyarakat ini adalah produk olahan yang dihasilkan yaitu Produk Atun dalam kemasan Vakum dan Tepung Atun Instan yang telah memiliki label dan layak untuk dipasarkan. Kemasan dan label yang telah 
didesain oleh tim Pengabdian Iptek berbasis Teknologi Hasil Pertanian, Fakultas Pertanian,

Dosen dan Masyarakat.

\section{Saran}

Saran dari tim Pengabdian IPTEK berbasis

Dosen dan Masyarakat di Nagari Lubuk Besar

Kecamatan Asam Jujuhan Kabupaten

Dharmasraya ini yaitu program pengabdian masyarakat sebaiknya dilakukan berkelanjutan setiap tahunnya untuk meningkatkan kualitas dan pemasaran produk Atun sebagai olahan Khas Daerah.

\section{UCAPAN TERIMA KASIH}

Penulis mengucapkan terima kasih kepada pihak-pihak yang mendukung terselenggaranya kegiatan Pengabdian masyarakat pada Kelompok Wanita Lubuk Besar Bersinar dan Kelompok PKK Nagari Lubuk Besar di Nagari Lubuk Besar Kecamatan Asam Jujuhan, Kabupaten Dharmasraya., yaitu LPPM Universitas Andalas, Kenagarian Lubuk Besar, Kecamatan Asam Jujuhan dan Jurusan
Universitas Andalas.

\section{DAFTAR PUSTAKA}

[1] Buckle, K. A., Edwards, R. A., Fleet, G. H., and Wotton, M. 1987. Ilmu Pangan. Penerjemah Hari Purnomo dan Adiono. Universitas Indonesia Press. Jakarta.

[3] Astawan, M, C.C.Nurwitri, Suliantari, Dicki Aulia Rochim. 2015. Kombinasi Kemasan Vakum dan Penyimpanan Dingin untuk Memperpanjang Umur Simpan Tempe Bacem. Jurnal PANGAN, 24(2):125-134

[2] Nur, Muhammad. 2009. Pengaruh Cara Pengemasan, Jenis Bahan Pengemas, Dan Lama Penyimpanan Terhadap Sifat Kimia, Mikrobiologi, dan Organoleptik Sate Bandeng (Chanos chanos). Jurnal Teknologi dan Industri Hasil Pertanian, 14(1):1-11 